\title{
A SUBJETIVIDADE NO CONTEMPORÂNEO EM FACE DO COMPORTAMENTO TRANSGRESSOR E A REALIDADE DO SISTEMA PRISIONAL BRASILEIRO
}

\author{
Adriano Andrade Barboza ${ }^{1}$
}

\begin{abstract}
Resumo: $O$ presente trabalho constitui-se num estudo teórico interdisciplinar entre as áreas da saúde, ciências humanas e sociais dividido basicamente em duas partes, a primeira objetiva, por meio de uma perspectiva culturalista a partir de referenciais teóricos da filosofia, da psicanálise, da psicologia e da sociologia, fazer uma análise em relação ao contexto e ao desdobramento social e cultural na subjetividade do ser humano contemporâneo, em especial àquele que se desvia das leis e acaba por infringi-las, culminando em sanções de encarceramento e segregação social. Enquanto a segunda busca trazer à tona dados sociais e estatísticos em torno do sistema prisional brasileiro, realizando, dessa forma, um breve retrato dessa estrutura social em que são analisadas suas mazelas e seus potenciais de solução. Pretende-se, contudo, apresentar uma discussão que promova questionamentos e reflexões dos temas abordados, permitindo, por sua vez, uma possível interlocução entre estes.
\end{abstract}

Palavras-chave: direitos humanos; sistema prisional; subjetividade.

\section{THE SUBJECTIVITY IN THE CONTEMPORARY IN FACE OF THE TRANSGRESSIVE BEHAVIOR AND THE REALITY OF THE BRAZILIAN PRISON SYSTEM}

\begin{abstract}
This work consists of an interdisciplinary theoretical study between the areas of health, humanities and social sciences divided basically into two sections. The first section, based on a culturalist perspective with references of theories of philosophy, psychoanalysis, psychological and sociological, seeks to make an analysis in relation to the context and the social and cultural unfolding in the subjectivity of the contemporary human being, particularly in terms of deviating from laws and breaking them - actions that lead to imprisonment and social segregation. The second section addresses data social and statistics from the Brazilian prison system and provides a brief report on the social structure in which this system's issues and potential solutions are analyzed. The overall goal, therefore, is to present a discussion that will inspire questions and reflections on the topics addressed and thus reveal any connections between them.
\end{abstract}

Keywords: human rights; prison system; subjectivity.

\section{LA SUBJETIVIDAD EN EL CONTEMPORÁNEO FRENTE AL COMPORTAMIENTO TRANSGRESOR Y LA REALIDAD DEL SISTEMA PRISIONAL BRASILEÑO}

Resumen: El presente trabajo se constituye en un estudio teórico interdisciplinario entre las áreas de la salud, las ciencias humanas y sociales dividido básicamente en dos partes, la primera objetiva, por medio de una perspectiva culturalista a partir de referencias teóricas de la filosofía, del psicoanálisis, de la psicología y de la sociología, hacer un análisis en relación al contexto y al desdoblamiento social y cultural en la subjetividad del ser humano contemporáneo, en especial al que se desvía de las leyes y acaba por infringirlas, culminando en sanciones de encarcelamiento y segregación social. Mientras que la segunda busca traer a la luz datos sociales y estadísticos en torno al sistema penitenciario brasileño, realizando de esa forma un breve cuadro de esa estructura social en la que se analizan sus mazelas y sus potenciales de solución. Se pretende, sin embargo, presentar una discusión que promueva cuestionamientos y reflexiones de los temas abordados, permitiendo a su vez una posible interlocución entre éstos.

Palabras clave: derechos humanos; sistema penitenciario; subjetividad.

\section{Introdução}

\footnotetext{
1 Atua como psicólogo clínico, graduado pela Pontifícia Universidade Católica do Paraná e pós-graduando em Psicologia Clínica: Abordagem Psicanalítica pela Pontifícia Universidade Católica do Paraná. E-mail: andradebarboza.prs@gmail.com.
} 
Ao adentrar no campo da subjetividade humana busca-se, neste trabalho, sobretudo, compreender a influência social e cultural que atinge o ser humano contemporâneo, pertencente a uma determinada sociedade, em particular, a brasileira, e, em especial, àquele que se torna desviante das leis e que acaba por infringi-las, culminando em sanções de encarceramento e segregação social. Conforme Bock, Furtado e Teixeira (2001), os fatores sociais e culturais permitem a configuração de um mundo interior, vindo a combinar uma série de aspectos que leva à experiência de uma vivência bastante particular. Em face disso, acredita-se que tais aspectos promovam a influência na configuração da subjetividade, possibilitando a construção de realidades num processo em que o ser humano pode vir a ser, ao mesmo tempo, produto do meio e construtor dele. Sobre a definição de subjetividade, referidos autores asseveram ainda que:

A subjetividade é a síntese singular e individual que cada um de nós vai construindo conforme vamos nos desenvolvendo e vivenciando as experiências da vida social e cultural; é uma síntese que nos identifica, de um lado, por ser única, e nos iguala, de outro lado, na medida em que os elementos que a constituem são experienciados no campo comum da objetividade social. Esta síntese - a subjetividade - é o mundo de ideias, significados e emoções construídos internamente pelo sujeito a partir de suas relações sociais, de suas vivências e de sua constituição biológica; é, também, fonte de suas manifestações afetivas e comportamentais (BOCK et al., 2001, p. 23).

No entanto, com base numa perspectiva socrática, é possível considerar e situar o sujeito como àquele que se encontra numa busca incessante de verdades, num embate que a duras penas pode render o prazer previsto por Freud, seja numa sociedade contemporânea considerada socialmente bem desenvolvida, ou não. Logo, se faz necessário pontuar que o prazer preconizado por Freud (2010) pode se realizar em decorrência de mecanismos como a sublimação, pelo processo de amar ou, ainda, atuar socialmente, de forma produtiva, num ofício que lhe gere satisfação. Nesse caso, é possível considerar a elaboração e a superação de conflitos subjetivos como um caminho para a satisfação, na medida em que aproxima o ser humano da experiência de descoberta ou ressignificação de valores identitários vinculadas ao processo de sublimação que o leva ao referido prazer.

No que se refere à sublimação, de acordo com Laplanche (2001), essa pode ser conceituada como sendo a sexualidade que acaba por ser controlada num movimento de economia sexual, vindo a resultar em uma utilização de pulsão sexual direcionada para as aquisições de cunho cultural. Pois, a sublimação vem a tratar-se de um mecanismo que substitui sua meta sexual para outro modo de satisfação que se torna mais elevada e se direciona para o campo da cultura, da arte ou da investigação e atividade intelectual, vindo a gerar uma satisfação legítima a qual se pode nominar, de forma consistente, como prazer. Sendo assim, no que se 
refere ao prazer, esse também pode vir a ser alcançado por meio do trabalho, desde que seja fruto de uma livre escolha, conforme discorre Freud (2010).

A partir da perspectiva sociológica de Touraine (2005), pode-se fazer uma interessante distinção entre os termos indivíduo e sujeito, que servem de base para uma análise em torno da ordem da heteronomia e autonomia, no qual o conceito indivíduo consistiria naquele ser humano que acaba de certa forma por ser moldado a partir de um processo cultural baseado num modelo de consumo, vindo a ser configurado pela sociedade, no qual são impressos os caracteres sociais pertinentes a uma determinada ótica cultural; enquanto que o sujeito viria a ser aquele que, direcionando-se para si, rebela-se e combate a situação de submissão, numa reivindicação de direitos e autonomia, passando, desse modo, a ser um combatente em busca de respostas diante de uma postura de questionamento e reflexão.

Contudo, no que tange a natureza do ser humano em relação à violência, de acordo com que aponta Canavêz (2013), é possível estabelecer uma demarcação correspondente à origem da violência que, num primeiro momento, pode se levar em conta o posicionamento de Hobbes que considerava o quanto o ser humano pode a priori possuir uma carga de animosidade e violência que lhe faz opositor aos demais, sendo considerado passível de ser isolado da comunidade para garantir a integridade daqueles que se portam em controle de comportamento agressivo sem ultrapassar os limites das liberdades alheias. Tal posição constitui-se distinta daquela que, por outro lado, é conceituada por Rousseau em que se concebe o ser humano como sendo puro e de origem benigna por natureza e que vem a ser alterado e direcionado para novas posições características a partir do fenômeno sociocultural.

Já, no que concerne à punição ao cidadão, o que se tem por referência é o processo de caráter punitivo condicionado a um conjunto de leis que, quando infringidas por este, pode leválo a sofrer sanções de privação de direitos e liberdade, a fim de ser apartado do convívio daqueles que aderem a tais regras estabelecidas e não as burlam. Contudo, o fato de apartá-lo do convívio social, não implica que esse deva ser submetido a condições degradantes, pelo contrário, deveria ser previsto processos que permitam a reelaboração identitária e exploração de suas potencialidades de sujeito, a partir dos parâmetros levantados por Touraine. Afinal, uma sociedade que se considera civilizada tem o dever de garantir assistência e contrapartidas aos seus cidadãos. Pois, segundo Veronese (2009), quando se tira a dignidade da criatura humana, esta tende a animalizar-se.

Conforme Foucault (1997), a origem da pena consiste numa forma primitiva de punição com caráter desumano de suplícios e execuções sangrentas em espaços públicos, visando estabelecer e dar manutenção à ordem pública. Com o passar do tempo e a partir do advento da 
Revolução Francesa e da Declaração dos Direitos do Homem e do Cidadão, foi possível conceber novos patamares de punições, menos desumanas, como às que se estabeleceram no fim do século XVIII e início do século XIX em várias partes do mundo e em Paris por Léon Faucher, em 1838, com o regulamento para a Casa dos Jovens Detentos de Paris, que concebia a regulação de privação de liberdade combinada com trabalhos e estudos regrados.

A fim de se promover uma pertinente reflexão, acredita-se como imprescindível conhecer melhor os elementos que regem a realidade do atual cenário do sistema prisional brasileiro com seus reflexos sociais que afetam a sociedade a qual pertence, pois, de acordo com Veronese (2009), os presos no Brasil vivem numa espécie de depósito de pessoas em terríveis condições de vida dentro dos presídios, que se transformam em uma bomba pronta para explodir extramuros. De acordo com a Lei no 7.210 - Lei de Execução Penal do Brasil - datada de 1984 (BRASIL, 1984), essa tem o objetivo de regulamentar o cárcere, bem como promover a reeducação do condenado a fim de prepará-lo para retornar ao convívio social, prevendo, ainda, em relação à lotação dos presídios no seu: “Art. 85. O estabelecimento penal deverá ter lotação compatível com sua estrutura e finalidade".

Nessa lógica, convém ressaltar que toda proposta prisional que vá ao encontro da aplicação da Lei em sua essência e que a leve a alcançar algum patamar de ressocialização deve ser enfatizada e analisada, pois abordar os meandros dessa realidade e suas deficiências é trazer à reflexão, inclusive e, sobretudo, as proposições no campo do encarceramento e da ressocialização que funcionam no país, ainda que venham a atender de forma reduzida o setor prisional se comparada à estrutura carcerária, então, considerada convencional e que abriga, por sua vez, a maioria do contingente de presos brasileiros. Descortina-se, dessa forma, a necessidade de análise sobre as possibilidades e soluções que visem atender a demanda por um processo de contenção criminal que, ao mesmo tempo, seja ressocializador.

O objetivo deste trabalho consiste em analisar a influência da estrutura social brasileira na configuração subjetiva do ser humano contemporâneo, que acaba por favorecer que este venha a se corromper a partir de um mecanismo produtor de consumo, vindo, em alguns casos, a se degradar, tornando-se um transgressor de leis e regras sociais, constituindo-se, assim, em um elemento que se torna marginalizado ou que vem a ser segregado do espaço social comum em que os cidadãos livres gozam da liberdade de ir e vir. Além disso, busca-se trazer à tona a realidade do sistema carcerário brasileiro, a fim de se fazer uma análise também dos vetores do Estado que promovem a ineficiência ou que deixem de promover melhorias, levando em conta, inclusive, as crueldades sociais. 
Desse modo, pretende-se realizar uma interlocução entre temas, cuja construção crítica permita amadurecer, sob o ponto de vista social, o processo de humanização e tratamento prisional, que pode se converter em benefícios para a sociedade como um todo e não só para o preso e ao segmento prisional brasileiro, como se poderia crer, num primeiro momento, de forma casuística.

\section{A Subjetividade no Contemporâneo em Face do Comportamento Transgressor}

De acordo com a perspectiva sociológica de Touraine (2005), há uma clara distinção conceitual entre indivíduo e sujeito, pois a partir de uma decomposição dos quadros sociais, emerge e triunfa o indivíduo, o qual se configura em um ser dessocializado, mas que encerraria em si um potencial de combate contra uma ordem social dominante e de forças contrárias à vida. Diante dessa conceituação, o indivíduo viria, portanto, a constituir-se em um molde pelo qual se projetam necessidades, desejos e ideais imaginários produzidos por uma indústria de comunicação de massa pela qual, esse indivíduo, acaba por vir a se encontrar numa posição de descaracterização identitária de individualidade e autonomia. Desse modo, viria a ser guiado para um processo esmagador que define e caracteriza a modernidade, cujo processo de fragmentação identitária e de sentidos próprios não permite ao ser humano atuar de forma consciente, e sim a reboque do movimento de uma lógica mercadológica e da indústria que visa o imediato e o consumo instituído por uma cultura vigente que movimenta esse sistema social.

Contudo, ao levar em conta o cenário contemporâneo como fenômeno estabelecido e descrito na realidade de sociedades contemporâneas por alguns teóricos, considera-se que essa vem a se tratar num elemento considerável de influência sobre o indivíduo, e por vir a se caracterizar, inclusive, na desconstituição identitária, na medida em que envolve o ser humano numa amarração de objeto e padronização, diluindo seus aspectos identitários de sujeito à lógica de mercado e ao comportamento de busca por satisfação imediata e consumo.

Por outro lado, de acordo com Touraine (2005), o sujeito viria a se constituir numa capacidade de evitar as forças ameaçadoras, o conjunto de regras, bem como os processos de poderes que promovem impedimentos de auto realização, de identificação e autonomia que lhe permitiria transitar naquilo que de fato é também por essência - sujeito. Nesse caso, o fenômeno da contemporaneidade pode ser considerado, também, como um fator que vem a ajudar a explicar um favorecimento de formatação do ser humano em indivíduo a ponto de reduzi-lo a peça de um sistema que influi sobre a sua atuação, atividade, intenção e interação em relação ao meio social. 
Diante da leitura de Touraine, configura-se, ainda, o sujeito como sendo um partícipe atuante da sociedade, vindo a ser influenciador do processo sociocultural, no qual se coloca num patamar de combatente e rebelde, cuja luta se caracteriza por promover uma oposição ao sistema de uma cultura homogeneizante, de uma mídia deformadora de sentidos e com determinações que visam fins baseados numa cultura utilitarista de processos de produção e consumo sem levar em conta as nuances idiossincráticas humanas, a liberdade, os desejos, as necessidades subjetivas e objetivas que configuram uma identidade e autonomia particulares.

A partir desses apontamentos, pode-se incluir a percepção de que não vem a ser uma tarefa fácil vir a tornar-se ou manter-se sujeito, pois que esse se caracteriza por questionamentos e enfrentamentos e, salvo algumas exceções, não se pode o tempo todo constituir-se combativo, pois o convívio social requer a adequação a algumas regras sociais, mesmo que, muitas vezes, não se concorde com estas, pois, será na alternância entre ser e não ser sujeito que se constituirá o indivíduo, objeto de molde social proveniente de direitos universais, culturais e políticos (TOURAINE, 2003 apud VERONESE; LACERDA, 2011, p. 422).

Neste aspecto, de acordo com Touraine (2005), é possível considerar que o status de indivíduo, por si só, pode guardar um latente potencial de insubmissão e de busca de autonomia que vem a ser mais proeminente e efetivo quando esse ser humano acaba por se posicionar como um ser questionador, reflexivo e combatente em busca de sua verdade que faça soar sentido de vida e lhe dê condições para construir seu papel não à margem da sociedade, mas em um movimento de romper fronteiras sociais que lhe eleve a condição de protagonista da sua vida e do contexto social no qual atua e realiza uma interação então como sujeito, o que vem a incluir o outro também numa possibilidade de mesma condição interativa e relacional.

No entanto, no que se refere a dilemas postos pela sociedade brasileira e por suas ilusões sociais de plena democracia e justiça no qual se configuram mecanismos de exclusão social, sustentados por uma base social a partir de um sistema econômico que, supostamente, englobaria a todos e os colocariam aptos ao jogo social; nasce e surge, portanto, o ser humano no seio desse corpo social civilizado, rodeado por uma cultura, cujos princípios serão norteados pela moral e por uma prática, sobretudo por uma prática que possui uma moral implícita. As ilusões que compõem esse conjunto cultural podem deformar sua condição de sujeito e aliená-lo daquilo que vem a ser a sua potencialidade. Afinal, esse indivíduo com "alma" de sujeito encontra diante de si uma cultura posta de preceitos preconcebidos que, de algum modo, pode determinar seu local de "nascimento", sua função e, às vezes, o seu destino por uma vida inteira. Pois, os modos de viver em sociedade são facultados por aspectos que consubstanciam uma posição favorável ou desfavorável para uma determinada realidade, quanto ao bem-estar e a saúde social do ser 
humano contemporâneo. No que diz respeito às circunstâncias do campo social na contemporaneidade, Lopes afirma que:

Enquanto a pobreza é um desdobramento das relações históricas e estruturais de oposição entre os interesses de classes, portanto, um fenômeno econômico que se configura na questão social derivada das relações capital $\mathrm{x}$ trabalho, a "exclusão social" se caracteriza por um conjunto de fenômenos que se configuram no campo alargado das relações sociais contemporâneas: o desemprego estrutural, a precarização do trabalho, a desqualificação social, a desagregação identitária, a desumanização do outro, a anulação da alteridade, a população de rua, a fome, a violência, a falta de acesso a bens e serviços, à segurança, à justiça e à cidadania, entre outras (LOPES, 2006, p. 13).

Em vista disso, quando condicionado a uma relativa posição de indivíduo, pode-se levar em conta, nesse caminho, a atuação de uma formação cultural midiática com todas as suas implicações e, sobretudo, numa oposição ao protagonismo do sujeito, pois vem a ser na possibilidade plena de expressão que se permitirá encontrar caminhos para transitar do papel de indivíduo para o de sujeito com aspirações ao protagonismo, inerentes ao ser humano sociável normativo.

Para a criatura humana, em especial para aqueles desfavorecidos no âmbito socioeconômico e submetidos a esse processo social formatador contemporâneo, muitas vezes, é como se a deformação do seu futuro já estivesse sendo moldada, em detrimento de uma cultura de consumo e exclusão social na qual, de modo geral, ao invés de haver acréscimos na sua formação, ocorre o inverso, há a subtração da manifestação daquilo que esse indivíduo possui de positivo de sua natureza questionadora. Como, por exemplo, na lógica de uma prova de redação de um vestibular, cuja avaliação começa pelo escore máximo e, na medida em que há a "correção" - a partir de uma formatação imponente e compulsória a pretexto de contrapartida de direitos e de um ser ideal na ótica imediatista de consumo - começam, então, por lhe descontar pontos pelos "erros" de insubmissão, ou seja, uma pontuação de trás para frente, vindo a ocorrer, assim, uma espécie de corrupção da sua condição inerente de sujeito.

É oportuno dizer que, conforme o tempo passe, esse sujeito pode se sentir como alguém que vai sendo influenciado, tornando-se formatado por completo pela sociedade alienante, a qual lhe apresenta uma cultura com contribuições para o bem e para o mal, uma vida ideal baseada no consumo e na satisfação hedonista e outra, real, na qual o indivíduo pode ficar apartado do bemestar social.

Sob essa premissa, Lopes discorre que:

[...] para Touraine, o sujeito resulta da reconstrução e recuperação da unidade do indivíduo - seu desejo de ser ator, seu esforço de subjetivação - como 
unidade consciente e com uma identidade. Permanecendo o indivíduo na dualidade, ele aceita os apelos do mercado e cai no consumismo desenfreado e acrítico. Não tendo essa possibilidade, sucumbe no mundo das drogas, da violência e dos excluídos do sistema. Os sujeitos excluídos do sistema encontram suas saídas na construção comunitária, nas redes solidárias e na solidariedade (LOPES, 2006, p.21).

Diante do exposto, é possível considerar que sob o condicionamento cultural com viés alienante se estabelecerá uma ausência de busca identitária que consiste na oclusão do sujeito que o encurrala numa condição mais predominante de indivíduo, vindo a lhe dar, assim, uma percepção de identidade artificial e insatisfatória. Desse modo, deixa-lhe sem capacidade de protagonizar a própria vida, vindo a ficar condicionado a um sistema perverso que lhe faz adentrar e circular no espaço social com deficiência, na medida em que não lhe faculta um aparato crítico sem prover o subsídio da contrapartida de cidadão com todos os direitos mediante suas obrigações e deveres.

O que buscar, então, como verdade nesse cenário de oposição ao sujeito a partir da perspectiva de Touraine? Vale considerar como legítimo o movimento de busca por uma verdade, quando o indivíduo consegue aspirar a tornar-se ator numa ação em que poderá viver como protagonista de sua vida sem amarras, com relativa autonomia. O que se coloca em questão, nesse processo, não é a busca por uma verdade lapidar que encerre questões - que seria um contrassenso ao processo de reflexão e de um princípio evolutivo -, mas a viabilidade do ato de buscar respostas em si, contendo, assim, implicações reflexivas. Análogo ao mito da caverna de Platão, conforme descrito por Chauí (2008), em que o ser humano consegue sair da obscuridade de uma vida virtual para uma vida real para fora da cápsula alienante. Nesse sentido, quanto ao potencial de sujeito encoberto, Touraine expõe:

[...] as sociedades mais ricas contemporâneas deleitam-se numa ideologia do consumo cada vez mais intenso e diversificado. E do mesmo modo que um pensamento repressivo recalca a procura do prazer, a nossa sociedade reprime e oculta à presença do sujeito. É no inconsciente que devemos procurar a vontade de ser sujeito (TOURAINE, 2005, p. 141).

Isto posto, conforme expõe Roudinesco (2016), Freud enfatiza que o "homem que pensa" vem a ser o único a decidir sobre suas questões, vindo a ser "seu próprio legislador, confessor e juiz", traduzindo-se, assim, na possibilidade de pensar e formular questionamentos que atravessam a sua existência e a condição de sujeito no mundo.

Para tanto, em relação à busca por relativa autonomia do sujeito, considera-se que a condução ao exercício reflexivo pode ser também facultada por um conjunto de fatores sociais essenciais em torno da dignidade e do desenvolvimento humano, no qual se permite configurar 
como estímulo para tal movimento. No entanto, esse é um processo capaz de se tornar aflitivo, quando se está alheio a um conjunto de condições e aparatos de acesso básico de cidadania e dignidade, pelo fato de necessitar da transposição dos preceitos estipulados que lhe caracterizam de forma polarizada em indivíduo. Ou seja, estar alheio a direitos fundamentais e dignidade pode ser determinante enquanto forma de favorecimento de distanciamento do indivíduo em relação a uma relativa autonomia, então atribuída, de forma mais específica, à condição de sujeito.

Por isso, deve-se considerar que quando não elaborado o processo de fazer-se também sujeito, a partir de condições ambientais e subjetivas favoráveis, será possível conceber algum tipo de angústia e insatisfação para este ser humano que não se põe a trabalho de uma elaboração subjetiva emancipadora e para qual poderia permitir que tal angústia viesse a se tornar um elemento portador de transcendência pessoal e que, de modo oposto, acaba, então, por levá-lo a uma condição de frustração sem inferência crítica e de ausente perspectiva de elaboração de conflitos subjetivos que poderiam ser realizados por um processo de produção reflexiva.

Conforme Pisetta (2008), no que se refere às considerações de Freud sobre a angústia, essa viria a ser considerada um afeto que antecede e causa o recalque, considerando-se que, desse modo, esta passa a ser uma evidência de que o princípio que regula o aparelho psíquico, que quer a obtenção de prazer, tal como a evitação do desprazer, acaba por falhar na sua ação. A angústia passa a ser, portanto, um anúncio de que o princípio de prazer-desprazer faliu, já que vem a ser percebida essencialmente como uma sensação desprazerosa. Contudo, a angústia guarda um potencial de elaboração subjetiva que pode permitir ao indivíduo superar-se e, portanto, principiar para uma condição reflexiva que vem a se caracterizar, de certo modo, no sujeito preconizado por Touraine.

No que se refere ao conceito de recalque, Roudinesco e Plon (1997) esclarecem que se trata de um termo que, para Freud, viria a designar um processo cuja meta reside em manter no inconsciente todas as representações e ideias ligadas à questão das pulsões, cujo movimento de realização, por ser produtora do prazer, afetaria o equilíbrio do mecanismo de funcionamento psicológico e psíquico do indivíduo que se transforma numa expressão promotora de desprazer por atuar como validação de algo inicialmente proibido e censurado então pelo superego. Por consequência, é possível considerar que a condição de indivíduo imobilizado por uma submissão a um processo cultural e social que lhe molda e engessa sua possibilidade de atuação com relativa autonomia e, sobretudo, sem as contrapartidas cidadãs, pode levá-lo a um quadro de angústia, insatisfação e sofrimento que se caracteriza numa implosão social, resultando de forma negativa numa busca de gozo a qualquer preço para contrapor uma frustração e insatisfação que 
se fazem presentificar na sua relação consigo mesmo e, por sua vez, com a sociedade a qual está inserido.

Segundo Chauí (2008), o posicionamento filosófico de Sócrates foi o de um radical, crítico com as opiniões estabelecidas, com os preconceitos da sociedade da época, com as crenças não questionadas por seus contemporâneos e pode muito bem nos remeter à concepção de sujeito de Touraine (2005) que se caracteriza ainda por se fazer atuante e protagonista no conjunto social.

O que vem, então, a significar ser cidadão numa sociedade com preceitos essenciais de cidadania estabelecidos que venham a ser atendidos? Pode significar um passo decisivo no sentido de favorecer o desejo de autonomia para o indivíduo, nos quais venham a ser considerados fatores que o dignifique e o implique perante o conjunto social e, que lhe faculte, inclusive, a busca do exercício de se tornar um ator social. Apoiado nessa leitura é possível entender que a cidadania pode ser também uma peça chave neste quebra-cabeça, sobretudo em sociedades em desenvolvimento, no qual pode ser considerado, em sua forma razoavelmente plena, a cidadania como contrapartida aos deveres e um movimento de inclusão social, na qual será possível angariar condições para proporcionar a possibilidade da busca por uma relativa autonomia, senso crítico e protagonismo, características então atribuídas ao sujeito. Em relação a essa condição de sujeito, Lopes expressa que:

A temática do sujeito necessita ser recheada de conteúdo social e político que ultrapasse as demandas do Ego e atenda às exigências da liberdade, da igualdade e da justiça. Não são meras especulações cognitivas, mas buscas concretas para uma melhor organização da sociedade, tornando-a mais justa (LOPES, 2006, p.21).

Dessa forma, vale salientar que o condicionamento de indivíduo acrítico numa sociedade perversa, que atue sem contrapartidas sociais de cidadania e inclusão social, parece contribuir também para conduzi-lo à margem das regras sociais e legais impostas, traduzindo-se, assim, no favorecimento às transgressões, aos delitos e no aumento da violência e da criminalidade.

No que toca às questões envolvendo aquele que se configura como desviante das leis e é sancionado ao encarceramento, é possível defrontar-se, nesse caso, com um conjunto de aspectos sociais e culturais que vem a promover condições subjetivas e de exclusão social que podem também facultar a este ser humano contemporâneo um caminho divergente das leis, vindo a se configurar em práticas consideradas delituosas.

A partir desses apontamentos, será possível dizer qual o nascedouro da transgressão e da violência em sociedades contemporâneas, sobretudo na brasileira cujo móvel se desloca em torno de uma cultura e fenômenos sociais diversos? 
Nesse caso, com o objetivo de responder tal questionamento, recorre-se a uma leitura subjetiva do sujeito em torno da transgressão e da violência que deriva para uma dialética de produto e produtor sociocultural de um fenômeno que surge de um movimento de autopreservação e de uma autodestruição em meio ao processo de produção de identidade atrelado a uma realidade pautada por vínculos utilitaristas de consumo, de competitividade e anulação de alteridade.

No que tange a transgressão, se faz necessário observar a moral coletiva como uma imposição de regramento, vindo a se constituir em algo a ser seguido coletivamente que pode, muitas vezes, não corresponder a um princípio que se movimenta com a devida fluidez diante daquilo que podemos considerar como um imperativo coletivo na prática social e que acaba por tentar se impor culturalmente. Afinal, existe uma prática que se sobrepõe a uma moral coletiva convencionada quando essa se estabelece de algum modo, por meio de um viés de violência, na medida em que se faz afirmar por mecanismos de poder sem levar em conta a realidade e nuances socioculturais dos sujeitos - uma imposição da Lei pela Lei - enquanto ocorre, então, por sua vez, outra moral oriunda e prevalente de uma prática social concebida pelo movimento natural dos comportamentos que resultam também na transgressão, como podemos ver todos os dias em noticiários no que diz respeito às pequenas corrupções cotidianas até grandes crimes envolvendo uma arquitetura de estruturas complexas de ordem coletiva.

Conforme Butler (2017), Adorno vem a afirmar que as questões morais apenas surgem quando o éthos coletivo deixa de imperar. Isso significa dizer que elas não vêm a surgir na base do éthos, e que comumente esse vem a ser aceito em consideração as suas qualificações morais. Nesse sentido, crê-se numa moral regida por uma prática social que se sobrepõe a moral coletiva generalizante estipulada como regra em forma de lei que, por não atender ou não levar em conta boa parte das idiossincrasias individuais, pode não se estabelecer como desejado em uma referência a ser seguida.

Por outro lado, de acordo com Silva Junior e Besset (2010), em termos amplos, permitese definir a violência como vindo a ser o exercício de um poder ou de uma força que se sobrepõe a outro, contra sua vontade e seu consentimento. Pois, analisar o contexto contemporâneo a partir dessa concepção de violência consiste considerar uma época na qual o que acaba por se pronunciar vem a ser o declínio do Nome-do-pai com a desorientação dos sujeitos submetidos então aos imperativos do gozo no discurso capitalista.

Nesse caso, é possível considerar que a transgressão e a violência são termos que se imbricam. Pois, a transgressão pode ser considerada um ato de rompimento, de invasão de espaços e ruptura de regras por meio de uma ação que vem a ser considerada como abusiva. Já, 
em relação à violência, é possível dizer que esta, se refere a um ato nocivo e lesivo que causa danos ou abalo, afetando uma estrutura individual ou coletiva. No entanto, é possível considerar, mais claramente, que a transgressão pode ser um modo de violência que visa romper barreiras ou regras para alcançar um fim. Nesse caso, observa-se que o ato de transgredir, cuja violência pode se manifestar num corpo coletivo ou individual, subjetivo ou objetivo, pode ser movido pela busca de um gozo que se constitui enquanto sintoma em substituição a um desprazer fruto da angústia que não cessa e, por não ser elaborada, demanda uma repetição do gozo.

Contudo, interessa perceber como se configura o sujeito nessa cadeia cultural de transgressão que implica em violência social e cultural. Pois, tais comportamentos transgressores, que derivam para infrações e delitos, acabam, em alguma medida, por serem atacados pela ação de repressão do Estado por meio da sanção legal de punição com privação de direitos e encarceramento, cuja segregação vem a se traduzir em um estado de condições que promovem consequências subjetivas e objetivas no apenado. Apenado, esse, que, num primeiro momento, deveria estar sendo direcionado para um processo penal visando à chamada ressocialização, então idealizada e que se faria reparadora de sujeitos considerados desviantes ou que não tiveram a chance de estabelecer um laço de cidadania produtiva com o Estado.

Pois, no que se refere à solução punitiva que se verifica no atual cenário social brasileiro, vem a tratar-se de um encaminhamento para a segregação penal que não leva em conta preceitos constitucionais que poderiam e deveriam levar o condenado ao cumprimento de pena de forma digna e mais promissora em relação a um tratamento ressocializador.

Além disso, a cidadania no seu sentido pleno representa um processo que deve atingir o cidadão independente de seu status de liberdade, seja ele livre ou aquele que acaba por estar temporariamente limitado do convívio social por sanções de encarceramento. Pois, a existência de um dispositivo para a responsabilização e reparação de atos delituosos cometidos é considerado como algo aceitável culturalmente e é visto como parte integrante do jogo social pelas sociedades, de maneira geral. Cabe, não obstante, questionar o melhor modo de fazer funcionar o processo de encarceramento que venha a resultar numa prática de justiça e não apenas em segregação sem mecanismos de reconfiguração social, pois a partir de dispositivos de promoção educacional, profissional e de dignidade poder-se-ia derivar em reconstrução de vida para o apenado que, como objetivo final, visaria a sua melhor e mais digna reintegração à sociedade. 


\section{Breve Retrato do Sistema Prisional Brasileiro}

Depois de considerar a influência sociocultural como parte integrante na condição objetiva e subjetiva do ser humano contemporâneo, levando em conta, ainda, a exclusão de direitos, verifica-se que o indivíduo oriundo de uma lógica de precariedades estruturais acaba por se configurar como um ente sem correspondentes elementos sociais de pertença em relação a uma sociedade ideal. Sociedade essa na qual ele pode acabar por consolidar-se como um indivíduo à margem social, vindo, desse modo, a derivar para um movimento de transgressão e violência correspondendo em práticas delituosas que podem resultar, por sua vez, no apartamento social por meio da sanção de perda de direitos e no encarceramento que, em sua maioria, se traduz em segregação pura e simples do indivíduo sem modos de ressocialização.

No que se refere à experiência prisional, no entanto, é observável que essa tem um potencial de influir sobremaneira na vida do detento, nos seus comportamentos presente e futuro em consequência do seu ingresso ao sistema carcerário em que são considerados a influência e implicações institucionais com suas especificidades conjunturais de uma estrutura que venha a se estabelecer de forma digna ou degradada.

Conforme o informativo da ONUDC.HIV (2015), o quadro dos presídios brasileiros é de precariedade, pois se traduz num processo avesso a condições básicas de saúde em que se verifica um hiperencarceramento com a disseminação de doenças como HIV e que, embora haja a distribuição de coquetéis de medicamentos para a doença, no entanto, o número total de seus infectados acaba por se constituir numa incógnita para as autoridades, demonstrando, assim, um abandono do Estado para questões essenciais de prevenção e atendimento de saúde e de dignidade nas instituições prisionais. Portanto, deve-se levar em conta que, além do aspecto psicológico devido à prisionalização em tais condições, os presos tornam-se reféns de uma realidade social que se revela perversa em torno do encarceramento no Brasil, pois é fato que chegam a esses presídios as camadas mais desprovidas da população, composta por pobres e negros com baixa escolaridade, segundo Veronese (2009).

As estatísticas nessa direção, de acordo com o sistema de informações estatísticas do sistema penitenciário brasileiro (INFOPEN), publicado em 2014, confirmam uma população carcerária brasileira constituída por $67 \%$ de pessoas de etnia negra e $31 \%$ de etnia branca, $1 \%$ de etnia amarela e $1 \%$ de outras. Para tanto, no que se refere à formação educacional, a maioria desse conjunto se encontra no enquadramento de escolaridade fundamental, composta, então, por $53 \%$ dos encarcerados com o ensino fundamental incompleto e $12 \%$ com o ensino fundamental completo (MINISTÉRIO DA JUSTIÇA, 2014a). A sequência de verificação de dados apresenta, ainda, a constatação de um percentual de $12 \%$ com o ensino médio incompleto e $7 \%$ de apenados 
com o ensino médio completo, sucedendo-se por $7 \%$ de alfabetizados via cursos irregulares e $6 \%$ de analfabetos, enquanto se verifica, nessa população, $1 \%$ com o ensino superior incompleto e somente outros $1 \%$ com o curso superior completo.

Arruda (2011) em seu texto sobre a ineficiência e as mazelas do sistema carcerário brasileiro, coloca em pauta o abandono e a falta de investimento por parte do poder público nos presídios no Brasil, cujo descaso ajuda a criar uma escola de aperfeiçoamento do crime dentro das prisões, além de gerar um ambiente degradado e pernicioso que vai de encontro com a dignidade humana. Contudo, quando se fala em investimento não se está considerando o dinheiro usado para cobrir despesas básicas, mas a adequação de uma aplicação mais eficiente que vise uma estrutura qualificada em dimensão ressocializadora. Pois, de outro modo, a atual situação dos presídios também vai contra o artigo 88 da Lei de Execução Penal (BRASIL, 1984), que prevê que deve haver compatibilidade entre a estrutura física e a capacidade de vagas, condições dignas e de salubridade, assim como é previsto nos artigos 10 e 11 da referida Lei, o dever do Estado no que se refere às assistências de saúde, psicológica, jurídica, educacional e outras que visam à integridade e bem estar físico, psicológico e social, bem como um movimento ressocializador para o preso no sistema prisional.

No que tange ao judiciário, e naquilo que lhe compete, observa-se a ocorrência de uma ineficiência no atendimento ao preso, na medida em que se tem notícia das chamadas sobrepenas e a morosidade da justiça que se configura em prejuízos e desajustes legais com graves danos à sociedade brasileira, conforme revelam Adorno e Pasinato (2007). Nesse caso, as consequências dessa ineficiência em torno do ato jurisdicional podem vir a resultar em fazer permanecer o detento aprisionado além do que deveria ou, ainda, mantê-lo preso indefinidamente à espera de um julgamento, que, nesse caso, conforme o Infopen, em 2014, configura-se em $41 \%$ das pessoas privadas de liberdade sem o julgamento devido, vindo, dessa forma, a contribuir para o inflacionamento do contingente carcerário (MINISTÉRIO DA JUSTIÇA, 2014a).

Por mais que haja um sistema mantenedor de despesas por meio de verbas direcionadas às unidades federativas, como no caso do governo central - num alto custo -, ainda assim não se constata tais recursos revertidos num projeto equânime de eficiente investimento, pelo contrário, constata-se a ausência de infraestrutura e salubridade no modelo vigente em grande parte das unidades prisionais no Brasil.

A realidade dos presídios brasileiros pode ser avaliada ainda por meio de contraste com modelos estrangeiros conforme descrições, como as feitas na obra de Soares (2012), exsecretário nacional de segurança pública, que apresenta a trajetória da prisão de um traficante de drogas brasileiro preso em Londres que, depois de passar pelas prisões britânicas, consegue 
transferência para o chamado inferno - prisão no Rio de Janeiro. Enquanto o presídio de segurança máxima inglesa previa celas assépticas com vigilância e monitoramento inspirados no conceito de panóptico de Bentham; no Brasil o condenado se defronta com a superlotação que deriva na realocação em delegacias lotadas e apinhadas de detentos em condições insalubres em que a corrupção permite alguns arranjos de acomodações privilegiadas, consideradas menos piores, mediante pagamento de mensalidades para os carcereiros, sendo que, nesse caso, alguns detentos podem pagar enquanto outros, não.

Segundo Ferreira (2012), no que diz respeito aos presídios brasileiros, há uma clara configuração de violações dos direitos humanos, ao direito penal, e no que compreende à própria Constituição Federal no sentido de não serem efetivados os direitos à saúde, à higiene, à educação e ao trabalho. Nessa sequência, o Sistema Penal Brasileiro veio a consagrar-se por meio do artigo 59 do Código Penal que possui uma teoria com mista finalidade referente à pena que é a de reprovar e prevenir o crime. Pois, além de existir uma legislação que se torna ineficiente diante de um papel presumido de eficiência que deveria ter o Estado diante da demanda desse segmento, demonstra-se que tal legislação não previne ou reduz os índices de criminalidade. Em virtude disso, a autora manifesta, ainda, que na atual conjuntura em que a administração pública preza pela eficiência, tanto nos aspectos financeiros quanto em resultados, acaba por se mostrar ineficiente diante de suas consequências no setor carcerário, indo, portanto, na contramão do interesse público.

Tais aspectos afetam não só a comunidade carcerária, assim como a sociedade como um todo, uma vez que os objetivos teóricos de ressocialização do Estado não são alcançados e a violência extravasa os muros penitenciários, seja pelo comando do crime por líderes de facções ou por conta de uma massa criminosa constituída por ex-detentos que saem da pena mais comprometidos com práticas delituosas ou devendo favores às facções criminosas vindo, assim, a reincidirem no crime com mais violência, conforme se constata pelos altos índices de reincidência após o cumprimento da pena no sistema prisional convencional.

Nesse sentido, convém observar que quando o Estado não atua de forma determinante na construção de dignidade e de organização racional nos presídios, acaba-se, nesse caso, por abrir brechas para que os detentos, a partir de lideranças criminosas, venham a se organizar em grupos, a pretexto de pleitear melhores condições prisionais, mas que acabam, no entanto, por configurar as chamadas facções, que, entre outras coisas, dão proteção ao preso, estipulam regras e comandam o crime, de forma efetiva, dentro e fora dos presídios.

A partir dessas avaliações, considera-se que não é possível pensar segurança pública sem levar em conta a questão dos presídios, uma vez que o processo de cumprimento de pena deveria 
levar o cidadão apenado ao regime de "resgate" social, num espaço em que ele se encontra sob os cuidados do Estado e, depois de cumprida a pena, poderia, com maiores chances, não vir a reincidir no crime.

No que corresponde ao índice de reincidência criminal, segundo o relatório de pesquisa do IPEA (2015), é possível perceber que os tipos de crimes imputados aos que se encontram apenados configuram-se, em grande parte, em crimes praticados contra o patrimônio, sendo que para esse tipo de infrator há ocorrência de 40,9\% referente aos números de processos, enquanto que, no que tange a reincidentes, esse percentual eleva-se para 50\%, sendo, portanto, o crime de furto o mais frequente em relação à totalidade de categorias criminais seguido de roubo e tráfico de drogas. Esse mesmo relatório do IPEA (2015) apresenta, entre outros dados, entrevistas realizadas com detentos oriundos dos regimes fechado e do semiaberto no qual expressam que a possibilidade de reinserção social depende de seus esforços pessoais em combater os efeitos nocivos que o processo de encarceramento veio a inscrever em suas vidas, sendo a experiência do cárcere considerada como a pior já ocorrida em suas existências.

Dessas entrevistas, foi possível, ainda, fazer um recorte para um dos depoimentos em que um apenado do semiaberto atesta:

O sistema é uma coisa que nunca vai sair da minha cabeça porque sempre lembro. A experiência é só sofrimento e desprezo. Fica esquecido ali dentro. Só quem passa sabe, é muito sofrimento. Nós somos humilhados o tempo todo lá dentro. Aqui fora eu reflito para que eu não volte mais a cometer o que cometi. Pretendo fazer as coisas certas para nunca mais entrar ali, passar o que eu passei, não voltar para ali, nem passar na frente. Bola pra frente, seguir para criar os nossos filhos. Mas trauma, pensamento, a gente sempre tem (IPEA, 2015, p. 103).

Diante de tais constatações dos efeitos biopsicossociais do sistema prisional na vida do detento, torna-se importante vir a considerar outros caminhos que resultem em processos punitivos, que sejam menos degradantes e prejudiciais ao infrator e que busque melhores resultados no que se refere à reformulação e recondução social. De acordo com o informe do Ministério da Justiça (MJ) de 2012, apresentou-se, desde então, uma possibilidade de mudança de regras, a partir de um processo em que seria previsto a disponibilidade de verba específica com o objetivo de fomentar núcleos que visam a viabilizar as penas alternativas. Tais núcleos contariam com equipes multiprofissionais para atender à demanda, entre outros aparatos, o que veio a se tornar uma realidade posteriormente. Pois, segundo o Ministério da Justiça (2014b), as penas alternativas passam a mostrarem-se uma prática viável e mais promissora que vem sendo amadurecida e implantada nos últimos anos. Além disso, a partir dos informes oficiais e relatos 
de especialistas, há a constatação da diminuição de reincidência de crime nos casos em que é executado esse tipo de pena.

Levando em conta essa possibilidade, é possível considerar que a aplicação de penas alternativas consolida um caminho de reparação de dano cometido fazendo com que o condenado atue socialmente de forma reparatória e educativa diante do delito, promovendo, assim, também um desafogamento prisional e a possibilidade de não mais incidir no erro, como acontece na maioria dos casos.

Outro processo que se faz importante observar, são as iniciativas de presídios-modelo ou presídios-indústria, pois, de acordo com Botelho (2013), em presídios com viés ressocializador, com condições dignas e que se encontram administrados sob o controle da chamada APAC, por exemplo, não há a existência de policiais, sejam civis ou militares e, no entanto, os detentos possuem chaves de todas as celas e também dos portões da unidade. No caso dessa instituição, conforme Vasconcellos (2014) se confirma um índice de reincidência entre 8\% a 15\%, enquanto que o percentual atribuído aos presídios convencionais é de $70 \%$.

No que tange à Penitenciária Industrial de Guarapuava, cuja administração também é terceirizada, são oferecidos aos presos serviços de alimentação, assistência médica, jurídica e psicológica, além das atividades de rotina, possuindo um índice de reincidência de apenas $6 \%$. No entanto, tem sua capacidade de vagas limitada em 240 detentos, como discorre Osório e Vizzotto (2005).

Diante desses dados, é possível atribuir a proposta de presídios-modelo como um conjunto de fatores positivos que podem repercutir no processo ressocializador como se demonstra no caso das APACs, da Penitenciária Industrial de Guarapuava e de outras similares, para ambos os casos de presídios-modelo ou industrial, cuja realidade prisional se configura em direitos humanos envolvendo detentos e funcionários do sistema prisional, então atendidos com suporte e estrutura, que visa à promoção social, servindo, esse modal, portanto, de contraponto às mazelas e degradações observadas nas instituições convencionais, que são a maioria no país.

No entanto, os presídios considerados convencionais dão sinais de sobrecarga e falência, pois conforme levantado a partir dos informes do Ministério da Justiça, ao longo dos últimos anos, presencia-se uma elevação de números crescentes da população carcerária em ritmo contínuo, no qual se amplia o déficit de vagas, vindo a se caracterizar em uma superlotação dos presídios e cadeias. Assim, é possível enfatizar uma certificação em relação à superlotação e um aumento sistemático da população carcerária num recorte temporal de dez anos, no qual se caracteriza, na primeira década analisada por este trabalho (1995 a 2004), a ocorrência de um crescimento elevado para o período em que, segundo Ministério da Justiça, houve o primeiro 
censo penitenciário de âmbito nacional, então iniciado em 1993 (SALLA, 2012 apud MINISTÉRIO DA JUSTIÇA, 2014b), não havendo, no entanto, uma série histórica que se caracterizasse de forma consistente e contínua.

De toda forma, após 2004 foram constatados avanços no que se refere ao censo demográfico e dados do sistema prisional a partir do lançamento do Infopen, criado em 2004 pelo Ministério da Justiça. Por esse motivo, conseguiu-se apenas extrair informações pontuais referentes aos anos específicos de 1995 e 2004 divulgados pelo Ministério da Justiça, pelo qual se permitiu apresentar a evolução da primeira década analisada, pré-Infopen.

Segundo os dados do Ministério da Justiça (2014a), é possível verificar o crescimento da população carcerária no Brasil no período entre 1995 a 2004, no qual houve um aumento aproximado de 127,30\%, cujos números apresentam um contingente de apenados de 148.000 em 1995, saltando para 336.400 em 2004. A configuração de aumento médio populacional no sistema prisional ao longo dessa década foi então de 12,73\% ao ano. Cabe enfatizar que as informações apresentadas sobre o aumento da população carcerária, ao longo dos anos, são relevantes e permitem uma averiguação consistente e passível de uma reflexão acerca do quanto o sistema prisional brasileiro precisa e pode se aprimorar para, inclusive, atender ao seu déficit de vagas.

No entanto, essas questões prisionais e criminológicas, envolvendo índices de aumento populacional, permitem que se considere que a causa da elevação demográfica da população carcerária brasileira vai além de um mero olhar focalizado na lotação institucional do sistema prisional e que, num primeiro momento, demonstraria uma pseudoeficiência de prender e fazer justiça, pois a busca por levantamentos apurados da população carcerária possibilita, sobretudo, a construção de estratégias para um objetivo de redução da violência dentro e fora dos presídios.

De toda forma, o levantamento do crescimento da população carcerária, ano a ano, baseado em informação sólida e contínua, pode dar uma dimensão de um processo de política pública de segurança que superlota presídios e aumenta o déficit de vagas sem equacionar o problema de maneira humana e racional. No que se refere à base estatística, mais recente, da segunda década analisada (2005 a 2014), em relação ao crescimento da população carcerária que, desde 2004, passou a ser efetuado pelo Infopen, vem a demonstrar a evolução de crescimento da população carcerária em conformidade com os relatórios oficiais publicados do censo do setor em 2014 pelo Infopen do Ministério da Justiça (2014a) por meio do Departamento Penitenciário Nacional (DEPEN). Tal documento, inicia sua contabilização no ano de 2005 com um total de 361.400 presos no sistema carcerário e que, de forma linear, segue, ano a ano, até 2014, cujo contingente dessa população alcança o número de 607.700 encarcerados. Essa verificação, pós- 
Infopen, demonstra uma queda de crescimento médio para um índice de $6,8 \%$ ao ano. No entanto, no que se refere ao índice e ao ritmo de crescimento da população carcerária, pode ser considerada, ainda, preocupante se comparada ao crescimento demográfico da população brasileira, que fica em torno de $1 \%$ anual para esse período, conforme dados e projeções do IBGE (2013).

Trata-se, portanto, de um salto considerável de crescimento para uma década (2005 a 2014), embora tenha ocorrido uma redução relevante de crescimento de quase $50 \%$ em relação à primeira década analisada (1995 a 2004). Tal índice de crescimento, no entanto, demonstra um desajuste social, cuja violência revela um vetor incontrolável na sociedade, pois que a estrutura prisional não dá conta de abrigar equitativamente seus presos que se multiplicam e se mantêm produtores de crime após o cumprimento de sentença, em grande parte dos casos.

Para tanto, observa-se que o Brasil apresenta, de forma persistente, um déficit de vagas que, em 2014, chega a mais de 230.000, ou seja, mais de um terço de sua população de presos está excedente na estrutura prisional em relação a sua capacidade de abrigar adequadamente e de forma equânime, o que faz, inclusive, com que as alocações de detentos se direcionem também para delegacias, cuja função original é de prisões de custódia provisória. Contudo, visando uma atualização estatística, verifica-se, via Infopen que, em 2016, o contingente prisional alcançou o número de 726.700 presos no sistema prisional brasileiro (MINISTÉRIO DA JUSTIÇA, 2017). Diante de tais constatações, considera-se como inviável pensar políticas para a área de segurança sem levar em conta o atendimento do sistema prisional, no qual se constitui, com seu quadro de superlotação e deficiências, numa promoção de um conjunto de consequências que vem a afetar e sobrecarregar a estrutura de segurança pública de forma inexorável. Além disso, ao verificar essa realidade em dados, constata-se a responsabilidade do Estado pelo cidadão de sua sociedade, sem conseguir atender a demanda social no viés preventivo, acabando, portanto, por atacar a violência nas suas consequências de forma paliativa, fato que acarreta mais violência e degradação social, criando, assim, forte impacto nos custos sociais e econômicos para o país.

Todavia, ainda que num ritmo menor do que na década de 1995 a 2004, o período posterior, de 2005 a 2014, mostra os números de crescimento da população carcerária ano a ano, que acaba por onerar financeiramente o sistema e gerar um processo para este que se faz ausente de condições mínimas de higiene e de saúde física e mental para o contingente prisional. No tocante ao custo financeiro específico do detento para o Estado, é possível mensurar o custo social gerado para a sociedade brasileira ao verificar o quanto pode custar um preso ao Estado em contraponto a um estudante da rede pública do ensino básico, conforme os dados extraídos do Conselho Nacional de Justiça (CNJ) e do Fundo Nacional de Desenvolvimento da Educação 
(FNDE). Tais dados, apontam que o custo financeiro médio mensal aproximado de um preso brasileiro, em 2015 , foi de $\mathrm{R} \$ 3.000,00$, constituindo-se num gasto anual de $\mathrm{R} \$ 36.000,00$ por preso, enquanto o custo médio mensal de um aluno de ensino básico da rede pública no país, projetado para 2017, é de $\mathrm{R} \$ 239,59$, vindo a se configurar em um custo médio anual de $\mathrm{R} \$ 2.875,03$ por estudante (FNDE, 2016).

A exposição dos números dos custos per capito de um preso versus um aluno da rede pública demonstra claramente a desproporcionalidade de investimento em estruturas sociais a partir de seus resultados, pois ações e investimento em processos de rede social podem contribuir na prevenção de riscos de pobreza extrema, da violência e da criminalidade. Nesse caso, parece pertinente pontuar que o valor gasto com um preso poderia ser investido de forma mais eficiente numa prisão digna com melhores condições, pois esse alto gasto prisional é fruto da ingerência e a ausência de fortalecimento de políticas públicas que poderiam ser mais bem atendidas e resultarem em efeitos menos danosos à sociedade brasileira.

Nessa perspectiva, torna-se importante considerar que todas as propostas que levem a alcançar algum nível de ressocialização devem ser evidenciadas, permitindo, inclusive, abrir a discussão para modelos de unidades sob tutela estatal, privatizada ou mista nas chamadas Parcerias Público-Privadas (PPPs) para o setor no qual se considera o gerenciamento e a gestão monitorada pelo Estado, assim como por outros mecanismos sociais de fiscalização. Embora tais propostas venham a ser fruto de críticas por alguns, como é o caso de Midvit e Gruber (2013) que discorrem sobre uma visão do preso como mercadoria do capitalismo em relação ao sistema privado. Por outro lado, é possível se levar em conta os aspectos positivos de salubridade e condições de boa infraestrutura e estrutura social, que atuam nessas unidades citadas de forma mais promissora e na maioria dos casos desse tipo de gestão no país. Entretanto, o epicentro do problema indica ser realmente o processo de gestão, pois descobrir como fazer esse processo acontecer de forma satisfatória, parece ser uma grande questão a ser resolvida, a fim de priorizar uma nova política prisional contando com modais de gestão pública, privada ou mista, mas cujo modelo venha, sobretudo, objetivar melhores resultados sociais para o setor e para a sociedade na qual está inserido.

\section{Considerações Finais}

A partir deste trabalho, elaborou-se uma leitura sobre certa influência sociocultural na subjetividade do ser humano contemporâneo em face ao comportamento transgressor a partir de fatores como exclusão social, cultura de consumo, ausência de cidadania e de justiça social que podem favorecer e incidir no ser humano uma possível condição polarizada de indivíduo, 
segundo a perspectiva teórica de Alain Touraine, cujos efeitos podem levá-lo, sobretudo, à margem da sociedade e à quebra de leis e regras sociais para atender uma demanda do apelo de consumo produzida por uma mídia massificada que alimenta a um projeto ancorado numa cultura de alienação identitária de individualidades.

Contudo, ficou, ainda, evidenciado que a condição de sujeito, que compreende uma capacidade de autorreflexão e atuação em prol de uma relativa autonomia, pode ser favorecido e mobilizado por meio de uma vivência experiencial com elementos promotores de cidadania e saúde social essenciais, que podem ser agentes produtores e auxiliares na implicação do indivíduo em sujeito, vindo a contribuir para elevá-lo ao campo de atuação na sociedade com mais protagonismo, inclusive, como um possível ator social.

Isso significa dizer, que foi considerado, neste trabalho, o fator de influência cultural e social no modo de vida do sujeito a partir de seus elementos subjetivos, assim como também os objetivos. No entanto, cabe destacar que tal influência sociocultural não determina o funcionamento estrutural de constituição da subjetividade humana que realiza a articulação de fatores internos e externos no ser humano, vindo a produzir, assim, uma determinada realidade. Nesse caso, é possível considerar que o funcionamento de tal mecanismo de subjetividade realiza-se de modo independente ao tipo de incidência sociocultural a que o sujeito venha a ser exposto e do qual ele apreende tais elementos socioculturais de forma seletiva e singular, tornando-se, assim, o fenômeno da subjetividade um processo único para cada ser humano, muito embora haja pontos comunicativos em comum com outras subjetividades via campo objetivo e interacional de linguagem, vindo, assim, a permitir que se estabeleça um determinado contexto sociocultural e de realidade que, por sua vez, incide nos modos de vida dos sujeitos envolvidos e vinculados por uma determinada cultura e seus respectivos laços sociais.

No que se refere a uma leitura e descrição da realidade do sistema prisional brasileiro referente a um período prioritário recente de vinte anos, entre os anos de 1995 a 2014, aos quais são incluídos ainda alguns dados de outros indicadores sociais mais atuais, apresentou-se uma análise com dados que resultou num breve retrato do sistema prisional brasileiro envolvendo questões em torno da eficiência e a efetividade do Estado em realizar políticas públicas e sociais para o setor, abordando, assim, aspectos qualitativos de salubridade, direitos humanos e legais para a população carcerária.

Diante dos desafios e dos objetivos desse estudo, este se configurou, ainda, na verificação de medidas de melhoria e potenciais de eficiência, considerando soluções em torno de penas alternativas e pela opção de presídios-modelo que, embora estejam restritos a um número ainda 
muito reduzido no país, podem apresentar-se como uma proposta mais positiva sob o ponto de vista de direitos humanos, de saúde prisional e social.

Para tanto, coube considerar, ainda, uma análise da realidade social e de uma cultura de consumo associada a uma omissão de cidadania que leva a pensar na necessidade de discussões de políticas públicas e culturais que possam desconstruir e promover valores em torno de uma busca por relativa autonomia ou heteronomia não servil para sociedade, assim como se dirigir para questões sociais e de direitos humanos voltadas para o sistema prisional que, por sua vez, não deixa dúvidas de que, na atualidade, não possui um projeto para o setor com vistas à dignidade carcerária, à saúde mental e social por parte do Estado que se apresenta como o grande faltoso para o apenado que vive um regime de regras próprias estipuladas pelos líderes das facções criminosas.

Tendo em conta todos os fatores expostos, considera-se que o processo de saúde mental, nessas condições de degradação do ambiente e contexto prisional acaba por se demonstrar completamente comprometido a partir da precariedade no cumprimento da pena, cujas condições insalubres promovem a proliferação de crueldades e doenças, não permitindo que um preso, por mais bem intencionado que seja, consiga se colocar numa condição de cumpridor de pena pronto para retornar ao convívio social, pois os comprometimentos psicológicos e emocionais podem se tornar barreiras instransponíveis diante de uma realidade social na qual o ex-apenado que, depois de sobreviver à prisão, acaba por ser convocado a cair em reincidência, vindo a afastá-lo por completo da possibilidade de se tornar um cidadão com condições mínimas de saúde mental e social para se reintegrar adequadamente à sociedade com novas perspectivas.

Trata-se, portanto, da realização de uma análise em torno da influência sociocultural na subjetividade em um contexto contemporâneo que propicia condições para um modus vivendi idealizado no consumo, cuja sociedade, em muitos casos, não apresenta contrapartidas cidadãs que, por sua vez, implica em tornar as regras sociais inócuas diante da queda de autoridade do Estado enquanto grande Outro provedor e orientador de sentido legal, social e moral, tornando o conjunto social um contexto permissivo que pode favorecer a transgressão e degradação do indivíduo na sociedade a qual ele está vinculado.

\section{Referências}

ADORNO, S.; PASINATO, W. A justiça no tempo, o tempo da justiça. Tempo Social, Revista de Sociologia da USP, vol. 19, n. 2, ano 5, p. 131-155, 2007. Disponível em: <http://www.scielo.br/pdf/ts/v19n2/a05v19n2> Acesso em: 20/02/2018.

ARRUDA, S. N. Sistema carcerário brasileiro: a ineficiência, as mazelas e o descaso presentes nos presídios superlotados e esquecidos pelo poder público. Revista Visão Jurídica, São Paulo, n. 59, p. 2011. 
BRASIL. Lei no 7.210 de 11 de julho de 1984. Presidência da República. Casa Civil Subchefia para Assuntos Jurídicos. Diário Oficial [da] República Federativa do Brasil, DF, Brasília, 1984. Disponível em: <http://www.planalto.gov.br/ccivil_03/leis/L7210.htm> Acesso em: 01/10/2018.

BOCK, A. M. B.; FURTADO, O.; TEIXEIRA, M. L. Psicologias: uma introdução ao estudo de psicologia. 13. ed. São Paulo: Saraiva, 2001.

BOTELHO, A. W. A ressocialização do preso brasileiro. Inclusão digital e sociedade do conhecimento. E-GOV - Portal de e-governo, 2013. Disponível em: <http://www.egov.ufsc.br/portal/conteudo/ressocializa\%C3\%A7\%C3\%A3o-do-preso-brasileiro1> Acesso em: 03/10/2018

BUTLER, J. Relatar a si mesmo: crítica da violência ética. Belo Horizonte: Autêntica Editora, 2017.

CANAVÊZ, F. A violência a partir das teorias freudianas do social. Arquivos Brasileiros de Psicologia, Rio de Janeiro, vol. 66, n. 1, p. 33-48, 2013. Disponível em: <http://pepsic.bvsalud.org/scielo.php?script=sci_arttext\&pid=S1809-52672014000100004> Acesso em: 15/07/2018.

CHAUÍ, M. Convite à filosofia. 13. ed. São Paulo: Ática, 2008.

FERREIRA, P. G. A estrutura do sistema prisional brasileiro frente aos objetivos da teoria da pena. 2012. Disponível em: <http://www.ambito-juridico.com.br/site/index.php/?n_link=revista_ artigos_leitura\&artigo_id=12093\&revista_caderno=3> Acesso em: 10/09/2018.

FNDE. Ministro da Educação antecipa repasse do FUNDEB para garantir o pagamento do piso dos professores. 2016. Disponível em: http://www.fnde.gov.br/fnde/sala-deimprensa/noticias/item/9796-ministro-da-educa\%C3\%A7\%C3\%A3o-antecipa-repasse-dofundeb-para-garantir-o-pagamento-do-piso-dos-professores> Acesso em: 01/09/2018.

FOUCAULT, M. Vigiar e punir. Rio de Janeiro: Vozes, 1997.

FREUD, S. O mal-estar na civilização, novas conferências introdutórias à psicanálise e outros textos (1930 - 1936). Tradução: Paulo César Souza. São Paulo: Companhia das Letras, 2010.

IBGE. População: projeções e estimativas da população do Brasil e das unidades da federação. Brasília: Instituto Brasileiro de Geografia e Estatística, 2013. Disponível em: <http://www.ibge.gov.br/apps/populacao/projecao/notatecnica.html> Acesso em: 09/10/2018.

IPEA. Relatório de pesquisa: reincidência criminal no Brasil. Brasília: Instituto de Pesquisa Econômica Aplicada, 2015.

LAPLANCHE, J. Vocabulário de psicanálise/Laplanche e Pontalis: sob direção de Daniel Lagache. Tradução Pedro Tamen. 4. ed. São Paulo: Martins Fontes, 2001.

LOPES, J. R. Exclusão social e controle social: estratégias. Psicologia \& Sociedade, vol. 18, n. 2, p. 13-24, 2006. Disponível em: <http://www.scielo.br/pdf/psoc/v18n2/02.pdf> Acesso em: $16 / 10 / 2018$.

MIDVIT, M. H.; GRUBER, L. A. Privatização de presídio o sistema penitenciário brasileiro: uma crise. JICEX - Revista da Jornada de Iniciação Científica e de Extensão Universitária do Curso de Direito das Faculdades Integradas Santa Cruz de Curitiba, 2013. Disponível em: <http://www.santacruz.br/ojs/index.php/JICEX/article/view/235> Acesso em: 03/10/2018.

MINISTÉRIO DA JUSTIÇA - Portal do Cidadão. Informe: novas regras para criação de núcleos de penas alternativas. 2012. Disponível em: <http://portal.mj.gov.br/data/Pages/ MJC4D50EDBPTBRNN.htm> Acesso em: 03/10/2018. 
INFOPEN. Portal do Cidadão. Notícias: MJ divulgara novo relatório do Infopen nesta terça-feira. 2014a. Disponível em: <http://www.justica.gov.br/noticias/mj-divulgara-novorelatorio-do-infopen-nesta-terca-feira/relatorio-depen-versao-web.pdf>Acesso em: 03/10/2018.

Portal do Cidadão. Arquivo: alternativas penais - evolução. 2014b. Disponível em: $<$ http://www.justica.gov.br/seus-direitos/politica-penal/arquivos/alternativas-penais-1>Acesso em: 01/08/2018.

DEPEN. Levantamento nacional de informações penitenciárias. In: SANTOS, Thandara (Org.); ROSA, Marlene Inês et al. (cols.) INFOPEN atualização junho 2016. Brasília: Ministério da Justiça e Segurança Pública, Departamento Penitenciário Nacional, 2017. Disponível em: <http://depen.gov.br/DEPEN/noticias-1/noticias/infopen-levantamento-nacionalde-informacoes-penitenciarias-2016/relatorio_2016_22111.pdf> Acesso em: 04/10/2018.

OSÓRIO, F. M.; VIZZOTTO, V. D. Sistema penitenciário e parcerias público-privadas: novos horizontes. Revista Jus Navigandi, Teresina, ano 10, n. 882, 2 dez. 2005. Disponível em: <https://jus.com.br/artigos/7643>. Acesso em: 01/08/2018.

ONUDC. HIV no sistema prisional, e atuação das forças policiais e operadores do direito e o HIV são tema do primeiro GT/UNAIDS de 2015. Brasília: ONUDC, 2015. Disponível em: $<$ https://www.unodc.org/lpo-brazil/pt/frontpage/2015/03/09-hiv-no-sistema-prisional-e-aatuacao-das-forcas-policiais-e-operadores-do-direito-e-o-hiv-e-tema-do-primeiro-gt-unaids-de2015.html> Acesso em: 06/07/2018.

PISETTA, M. A. A. M. Considerações sobre as teorias da angústia em Freud. Psicol. Cienc. Prof., vol. 28, n. 2, p. 404-417, 2008. Disponível em: <http://pepsic.bvsalud.org/scielo.php? script=sci_arttext\&pid=S1414-98932008000200014 > Acesso em: 09/10/2018.

ROUDINESCO, E. 1944 - Sigmund Freud na sua época e em nosso tempo: Elizabeth Roudinesco. Tradução: André Telles. Revisão técnica: Marco Antônio Coutinho Jorge. 1. ed. Rio de Janeiro: Zahar, 2016.

ROUDINESCO, E.; PLON, M. Dicionário de psicanálise. Rio de Janeiro: Jorge Zahar, 1997. Disponível em: <https://pt.slideshare.net/JoseGeraldoMoreira/roudinesco-eplonmdicionariode psicanalise> Acesso em: 05/10/2018.

SILVA JÚNIOR, J. N.; BESSET, V. L. Violência e sintoma: o que a psicanálise tem a dizer? Fractal: Revista de Psicologia, Rio de Janeiro, v. 22, n. 2, p. 323-336, maio/ago. 2010. Disponível em: <http://www.scielo.br/scielo.php?script=sci_arttext\&pid=S1984-0292201 0000800008> Acesso em: 22/09/2018.

SOARES, L. E. Tudo ou nada. Rio de Janeiro: Nova Fronteira Participações S.A., 2012.

TOURAINE, A. Um novo paradigma para compreender o mundo de hoje. Lisboa: Instituto Piaget, 2005.

VASCONCELLOS, J. CNJ recomenda expansão das APACs para a redução da reincidência criminal no país. Agência CNJ de Notícias, 2014. Disponível em: <http://www.cnj.jus.br/ noticias/cnj/61552-cnj-recomenda-expansao-das-apacs-para-a-reducao-da-reincidencia-criminalno-pais> Acesso em: 08/02/2017.

VERONESE, J. R. P. O sistema prisional: seus conflitos e paradoxos. 2009. Disponível em: $<$ http://www6.univali.br/seer/index.php/nej/article/viewFile/1636/1342> Acesso em: $10 / 10 / 2018$.

VERONESE, M. V.; LACERDA, L. F. B. O sujeito e o indivíduo na perspectiva de Alain Touraine. Soc. e Cult., Goiânia, vol. 14, n. 2, p. 419-426, 2011. Disponível em: <https://www.revistas.ufg.br/fchf/article/viewFile/17616/10568>Acesso em: 11/10/2018. 